\title{
If future generations had a say: \\ An experiment on fair sharing of a common-pool resource across generations
}

\author{
Mike Farjam*a, Stephan Wolf ${ }^{b}$ \\ ${ }^{a}$ Linnaeus University Centre for Data Intensive Sciences 8 Applications (DISA@LNU), Växjö, \\ Sweden \\ ${ }^{b}$ Chair of Contextual Economics and Economic Education, University of Siegen, Germany
}

\begin{abstract}
Through an online experiment with 682 participants, we test how inter-generational resource sharing is affected by granting veto power to later generations. We specifically study the over-use of a common-pool resource (CPR) by early generations at the expense of later generations and examine how the veto empowerment of later generations can be used to restrain egoistic tendencies. We compare sequential ultimatum and dictator games of various lengths and find that (1) the CPR consumption of early generations does not depend on the number of generations that follow them; (2) the veto empowerment of later generations leads to a fairer, but ultimately less efficient use of the CPR across generations; and (3) the vetoes are used more carefully if not only previous generations, but also future generations that do not yet have access to the resource are affected by the veto.
\end{abstract}

Keywords: fairness, intergenerational sharing, common-pool resource, online experiment, dictator game, ultimatum game

JEL codes: C91, D69, G56, G58

\section{Introduction}

"You are failing us. But the young people are starting to understand your betrayal (...) We will never forgive you. We will not let you get away with this." With these words, young climate activist Greta Thunberg addressed world leaders during the 2019 UN Climate Summit. In an earlier TV interview (DemocracyNow 2019), Thunberg argued that Fridays for Future activists "should also try to wake the adults up, because [...] their generation is the ones who are mostly responsible for this crisis, and we need to hold them accountable." We are observing a fundamental power struggle between those currently in charge and those who consider themselves to be negatively affected by today's decisions. This raises an interesting question: What would change if future generations were actually empowered to effectively veto the decisions made by today's leaders?

\footnotetext{
*Correspondance: Linnaeus University, 35195 Växjö, Sweden

Email address: mike.farjam@lnu.se (Mike Farjam*)
} 
This question is not simply a hypothetical one. Several proposals, such as veto councils (Padilla 2002), have been raised to promote inter-generational sharing, though such debates have not gained much momentum. In addition, mechanisms such as 'inter-generational contracts' have existed for centuries (Kabeer 2000) and are part of many western welfare states (Walker 1996). Installing an intergenerational mechanism to empower future generations as part of a climate change mitigation strategy is thus a possibility worth exploring.

To compare scenarios in which one party depends completely on the good will of others to scenarios in which the depending party can veto, economists compare behavior in dictator and ultimatum games (Charness and Gneezy 2008; Güth and Kocher 2014; Mallucci et al. 2019). Our online experiment examines chains of dictator games with a re-growing resource, in which each link in the chain (a generation) must divide the resource left by the previous generation. We compare this scenario to chains in which one player in the chain can veto (in an ultimatum game style) the decisions of all previous generations. We also vary the position of the vetoempowered player to study how the impact of the veto on subsequent generations affects the use of that veto.

A simple thought experiment may suggest that the consumption of the present generation would decrease if future generations had power over it. This empowerment would disrupt what Georgescu-Roegen (1975) called "the dictatorship of the present" (DoP). However, previous research has identified surprisingly high degrees of pro-sociality in similar social dilemmas, and the idea of "leaving a better world for our children" is present across many cultures (Kasser 2011). The accumulation of capital stocks over the last several decades is an indicator of this notion, and environmental degradation, given a pro-social present generation, is an unfortunate side-effect.

In the context of this article, we define a fair outcome as one that minimizes inequity (Fehr and Schmidt 1999), and we define egoism as any behavior that increases inequity to maximize one's own well-being. To date, most research on the fair distribution of resources - both theoretical and empirical - has focused on intra-generational sharing (Konow 2003). The inter-generationally unfair distribution of resources is a key issue in the climate change debate (Schuppert 2011), and experimental research on inter-generational sharing only emerged in the 2000s. One relevant case is the inter-generational utilization of finite and re-growing resources, which determines the depletion of fertile land and climate stability. The latter is particularly concerning for Fridays for Future activists. Today, the number of inter-generational CPR experiments has grown large enough to identify different subfields, addressing (1) resource-specific parameters (Fischer et al. 2004), (2) heterogeneous externalities (Janssen et al. 2011; Gampfer 2014), (3) institutional differences (Osés-Eraso and Viladrich-Grau 2011; Hauser et al. 2014; Delaney and Jacobson 2016; De Geest et al. 2017), (4) communication (Lopez and VillamayorTomas 2017), and (5) other-regarding preferences (Sadrieh et al. 2003; Velez et al. 2009; Grolleau et al. 2016). Although the above cited studies differ in specific aspects, they share a stylized resource utilization model with the following features: (1) a re-growing resource, (2) harvesting at point t may reduce or even deplete the resource stock from t to $t+1$, and (3) harvesting parties live for some time and 
then are replaced ('generations'), and generations may overlap (OLG models) or not (non-OLG models). Despite the relevance for actual long-term policy making, to the best of our knowledge, there have been no experiments to date addressing the question of how the DoP affects resource utilization paths between generations, which is the focus of this paper.

Assuming that policy makers are at least partially interested in the well being of future generations, it is useful to know how detrimental the effect of the DoP is, before considering the implementation of inter-generational mechanisms (Oullier 2013). A clean test of the impact of power asymmetry between generations would require comparison of the world as we know it with one in which the young generation has power - something that we usually cannot observe in the real world. An experimental framework allows us to artificially create such a scenario via controlled environments. The artificiality of the experiment is thus a strength that allows us to test an otherwise not-falsifiable claim. Furthermore, the controlled environment enables us to observe path dependencies in inter-generational sharing, that is, to observe whether the effect of the DoP accumulates over generations, with each generation following the example set by the previous generation, or whether it remains constant across time. In our experiment, we randomly assigned the position of participants within inter-generational chains to test various claims regarding inter-generational justice and the effect of the DoP.

\section{Experimental design and hypotheses}

Our baseline is a sequential multi-person Dictator Game $(D G)$ in which the resource quantity available during each sequence is double the amount left from the previous sequence (i.e., the resource is regrowing). We contrast this scenario with a sequential multi-person Ultimatum Game $(U G)$.

The original $U G$ was implemented by Güth et al. (1982) as an interaction between two individuals, where the proposer $(P)$ is endowed with some amount of money. $P$ suggests to the responder $(R)$ how to distribute the money between the two. If $R$ accepts the proposal, the split is realized as suggested; if not, both players receive nothing. The $D G$ was introduced by Kahneman et al. (1986) as a variant of the $U G$ where $R$ is passive and has to accept the suggested split. With payoff maximizing players, (almost) nothing should be sent from $P$ to $R$ and the (relative) proposals should be identical in DGs and UGs. However, most offers in the $U G$ are around 40-50\% share, and even in the $D G$, proposers on average offer around $25 \%$ (Cooper and Dutcher 2011). This suggests that individuals are driven by altruistic preferences (Engel 2011) even when strategic considerations are absent: in the $U G$, sharing equally may be rational to avoid rejection; in the $D G$, sharing is not compatible with pure self-interest. Seen from a different angle, the difference between $U G$ and $D G$ proposals suggests that the responder's veto power is a tool that affects proposer behavior.

In our experimental design, we extend the original $D G$ design to groups of three or five (henceforth, $d g 3$ and $d g 5$ ) instead of only two players. In the experiment players represent generations (see Figure 1 for a graphical representation of the treatments). The resource regrows between generations and how much of the resource regrows depends on the quantity left by previous generations. The results is 
a sequential dictator game, in which all but the final player act as a dictator towards the subsequent player (Bahr and Requate 2014). As every player has full control over her or his own endowment, the game represents the dictatorship of the present (DoP) which forms the baseline in our analysis.
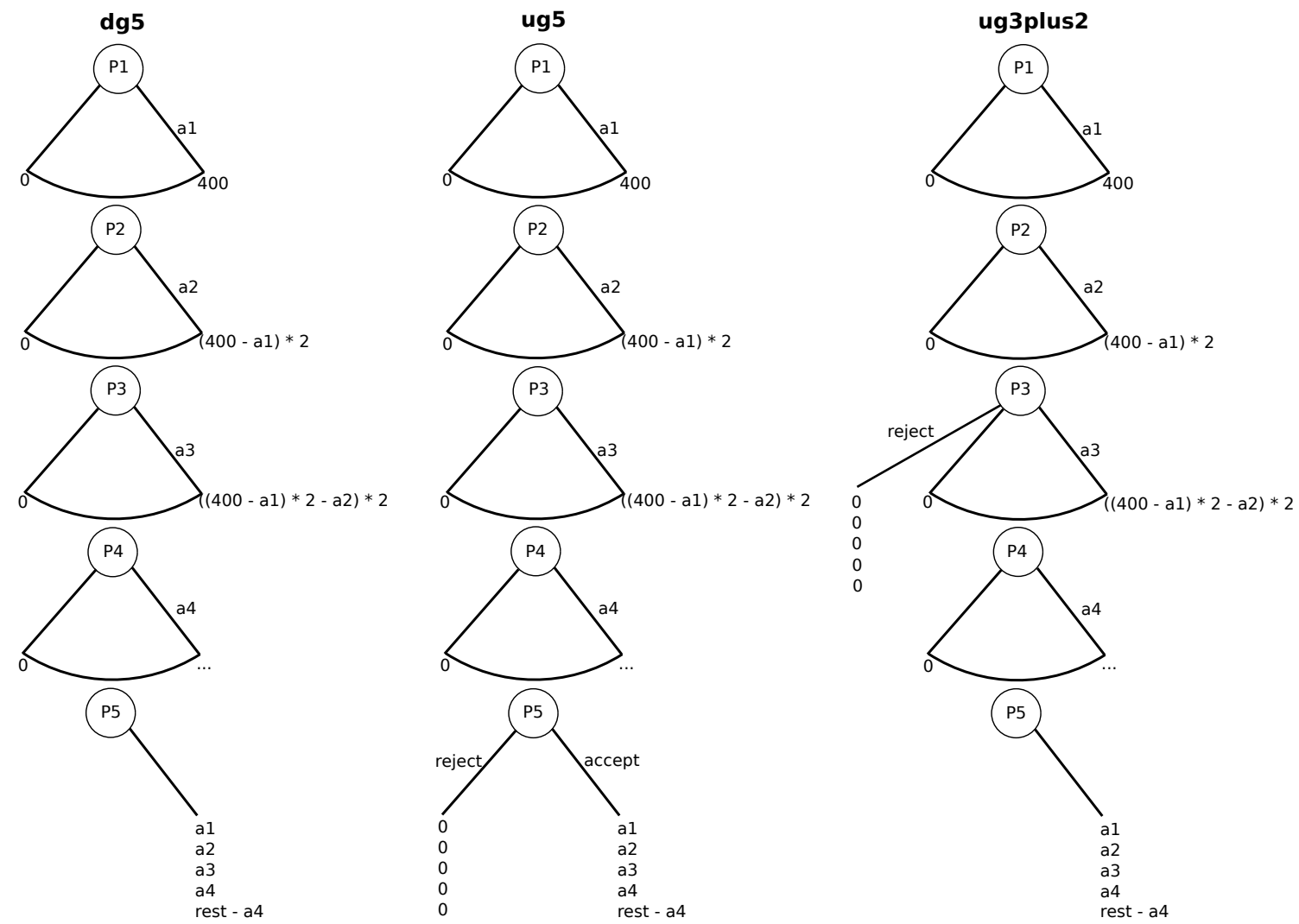

Figure 1: Treatments/games in extensive form. Treatments $d g 3$ and ug3 are not illustrated, because they follow the same dynamic as $d g 5$ and ug 5 but with shorter chains.

We expect resource sharing to change if later generations can oppose the decisions made by previous generations. Therefore, the most important experimental variable is whether or not a player has the veto found in the ultimatum game (henceforth, $u g 3$ and ug5): If the veto-empowered player rejects the resource distribution, no one receives a payoff; otherwise, the distribution is realized according to the players' claims.

Our central hypothesis is that in ultimatum games, the last player's payoff in ultimatum games will be higher than that in dictator games of the same length. To test how the time horizon of inter-generational sharing affects sharing, we also compare games with three generations to those with five generations. Furthermore, our design allows us to test for interactions between the length of the generational chain and the DoP. We expect that earlier players (in particular player 1) will claim less for themselves in the five-generation treatments compared to the corresponding three-generation treatments, because of some felt responsibility towards the larger number of future generations that are affected by their claim. This expectation is based on the findings of Riedl et al. (2003) and Bahr and Requate (2014) who find that proposers tend to increase offers when there are additional receivers. Fur- 
thermore, because we expect earlier players/generations to have a tendency to take more than $50 \%$ of resources for themselves, we expect that the last player will receive less in five-generation than three-generation treatments. As a consequence, we also expect acceptance ratios to be lower in $u g 5$ than $u g 3$.

Our last treatment, ug3plus2 is similar to ug3 but includes two additional players/generations, who continue the generational chain if player 3 accepts the proposal by the previous players. If player 3 rejects, all five players receive nothing. If the player accepts, player 3 receives the suggested endowment, and the game continues from that point as a sequential $D G$. Thus, at the time that player 3 must decide whether to accept or reject, players 4 and 5 took no decisions and player 3 must weigh a signal towards previous players against the well-being of later generations. By comparing ug3 with ug3plus2 we can isolate the effect of the felt responsibility towards future generations from the effect of the DoP. We abstain from formulating hypotheses for this treatment because it combines elements from both ultimatum and dictator games. Through this treatment, we can explore the motivations of the responder in the ultimatum game and the validity of our findings regarding the DoP for the real world which (usually) does not have a final generation.

\section{Method}

In total 682 participants were recruited via the crowd-sourcing marketplace Amazon Mechanical Turk (MTurk) and the experiment was programmed using oTree (Chen et al. 2016). To reduce within treatment variance, only US residents were allowed to participate (identified via their IP-address) and all data were collected on November 14 and 15, 2018 during the same two hours of the day. Participants received $\$ 1.5$ for taking part in the experiment, which took 12 minutes on average. Through the additional bonus (depending on the treatment and the decisions of group participants) they earned on average an additional $\$ 1.5$. To affirm participants' understanding of the instructions and to ensure that software bots did not participate, the participants had to correctly answer at least four out of five comprehension questions.

The experiment consisted of five treatments defined by the type of game that was played and the number of generations in the game. The participants were randomly assigned to the treatments, and each treatment contained approximately 32 groups (of three or five players). The treatments are illustrated as extensive form games in Figure 1.

Treatments $d g 3$ and $d g 5$ are sequential dictator games with three or five players, respectively. One participant was randomly assigned to the position of the first player and received an endowment of 400 Experimental Currency Units (100 ECU $=1 \$$ ). Player 1 could claim any amount between 0 and $400 \mathrm{ECU}$; the difference between the endowment and the claim was the remainder left. It is crucial to note that the endowment of player 1 was independent of the total number of players in the treatment (i.e., $400 \mathrm{ECU}$ in all cases). This remainder was then doubled, and given to player 2 as her or his endowment (i.e., if the first player took everything, all subsequent players would receive a zero endowment). The resource that the participants shared thus grew linearly which made it relatively easy to oversee the consequences of individual consumption. The last player in the chain received only 
what was left by the penultimate player. This final remainder was not doubled in order to make it easier for all players to compute the fair sharing scenario in which every generation except for the last consumes half of the endowment.

The treatments were constructed such that the resource allocations were most efficient (maximal total harvest) if early players took nothing and left the resource for later players. If all players except the last player took half of the endowment offered to them, each player would receive 200 ECU irrespective of the number of players in the treatment. Throughout the paper, we refer to this scenario as the 'sustainable' or 'fair' pattern and use it as a benchmark for evaluating our empirical results.

Treatments $u g 3$ and $u g 5$ were identical to $d g 3$ and $d g 5$ except for the fact that the last player could reject the proposed distribution of ECUs, leaving all players with 0 ECUs.

As a final treatment ug3plus2 was identical to ug3 with the exception that if player 3 accepted the proposal, the game would continue as a dictator game with player 3 as the first and player 4 as the second sequential dictator, and player 5 as the end-player (similar to $d g 5$ ). If player 3 rejected the proposal, all players, including players 4 and 5, would receive 0 ECUs.

\section{Results}

Our sample was relatively balanced in terms of gender (53\% female) and the participants had an average age of 35.4 years ( $\mathrm{sd}=9.6)$. As commonly found in studies on MTurk (Farjam 2020; Farjam et al. 2019), the participants leaned towards the political left (median $=4$ on a 0 -10 left-right scale). The demographics were equally distributed across treatments and all regression results reported below were robust towards the inclusion of these demographics as controls (see Appendix for more details).

As the first step in the analysis, we tested how the efficiency of resource use differed across treatments. The left panel in Figure 2 presents how much each player received on average from playing the game in their treatment (including inter-generational chains where veto players rejected). We see that (1) players on average received more when playing dictator games compared to ultimatum games, and (2) the reward per player was higher in three-player chains compared to fiveplayer chains. The first result can be explained by the costly rejections of receivers, which made ultimatum games less efficient. The right panel of Figure 2 demonstrates that players 1 seem to have anticipated the possible rejections in ultimatum games by claiming less of the endowment (compared to dictator games) for themselves and thus leaving more for the later players. However, the claims of the first players between games with three and five players were generally the same, suggesting that the differences in efficiency between treatments with three and five players are not explained by the claims of player 1 , but instead by the accumulated effect of the resource overuse by each generation.

The estimates for linear regression models presented in Table 1 demonstrate that the above described differences are statistically significant. We excluded ug3plus2 from these regression models because the treatment is essentially a hybrid between 
a dictator and ultimatum game and a three- and five-player game. We discuss ug3plus2 later in this section.
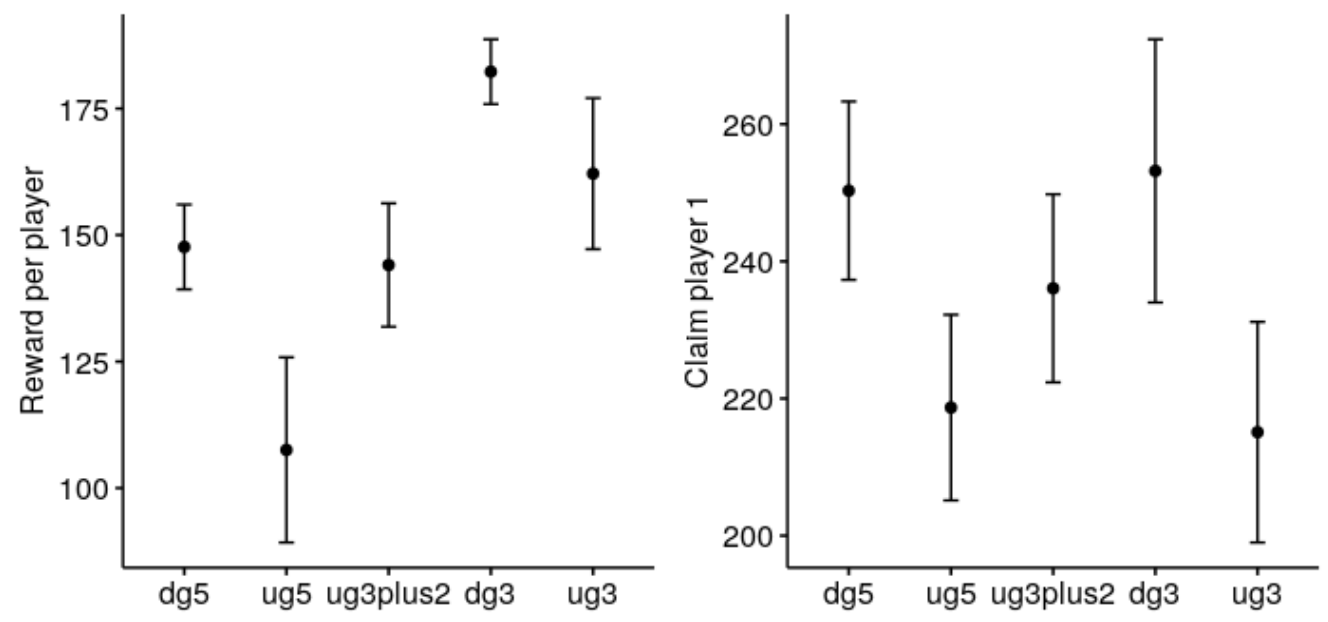

Figure 2: Means per group with standard errors.

\begin{tabular}{lrrrrrrrr}
\hline & \multicolumn{3}{c}{ Payoff per player } & & \multicolumn{3}{c}{ Claim player 1} \\
\cline { 2 - 3 } \cline { 7 - 8 } & Estimate & {$\left[\mathrm{CI}_{95}\right]$} & $p$ & & Estimate & {$\left[\mathrm{CI}_{95}\right]$} & $p$ \\
\hline Intercept & 187.222 & {$[165.4 ; 209.0]$} & 0.000 & & 251.579 & {$[224.8 ; 278.4]$} & 0.000 \\
5 generations & -44.535 & {$[-69.8 ;-19.3]$} & 0.001 & & 0.327 & {$[-30.7 ; 31.3]$} & 0.983 \\
Ultimatum & -29.898 & {$[-55.1 ;-4.7]$} & 0.021 & & -34.935 & {$[-65.9 ;-3.9]$} & 0.028 \\
\hline$R^{2}$ & 0.089 & & \multicolumn{5}{c}{0.037} \\
\hline
\end{tabular}

Table 1: Comparison of OLS estimates for models with the average payoff players received from the game (left) and the claim of the first player (right) as dependent variables (treatment ug3plus2 excluded).

Figure 3 provides a detailed view of the different ultimatum games and the decisions of the responders. The lowest acceptance rate was found in ug5 where slightly more than half of the responders accepted the resource allocation proposed by all earlier players. This rate was higher in $u g 3\left(\chi^{2}=3.424, p=0.06\right)$ and highest in ug3plus2 $\left(\chi^{2}=6.708, p<0.01\right)$. The differences between ug3 and ug3plus were not statistically significant. The right panel in Figure 3 illustrates that ordering treatments with respect to acceptance rates results in the same order as ordering with respect to the offers made to the responder. In other words, whether responders accepted an offer depended at least in part on the offer made to them, with the offer being least attractive in $u g 5$.

Our expectation was that the potential of a veto would discipline earlier players and thus save more of the resource for later generations. To better understand this phenomenon, Table 2 provides the claims (ratio of the endowment kept) of 


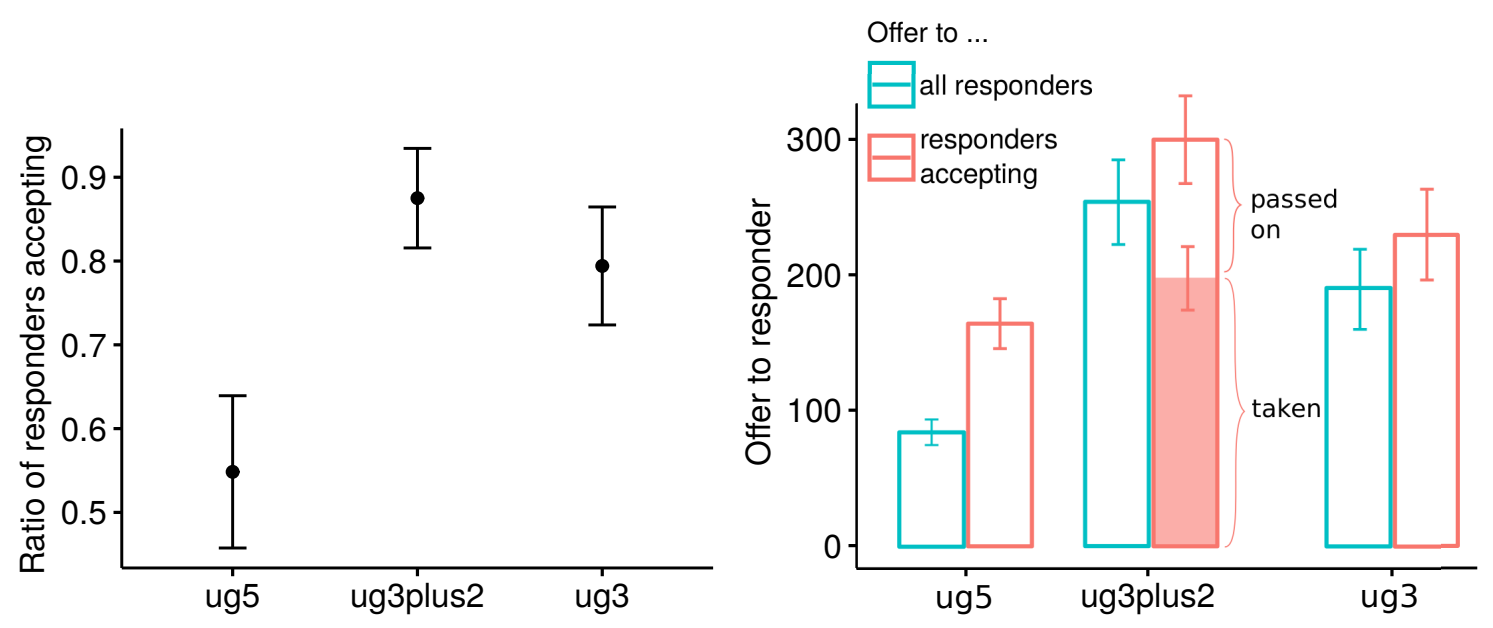

Figure 3: Comparison of Ultimatum Games. Left: the acceptance ratio of responders; right: the offers made to responders. Whiskers represent standard errors.

pre-veto $^{1}$ players in all treatments. The table shows that claims in general were slightly lower in ug- than in dg-treatments. Because of the design of the game, this difference in claims demonstrates that ug-treatments would have led to a more efficient (and equal) resource allocation had responders accepted all proposals. In the table we present claims separately for pre-veto players whose proposed distribution of resources was accepted or rejected by the responder. For the groups in which claims were accepted, the claimed ratio was very close to 0.5 , which corresponds to the distribution under which all generations received the fair amount of 200 ECU. This result is in sharp contrast to groups in which the proposal was rejected, where claims were much higher. To put the differences in claims into perspective, an average claim of 0.5 implies that the responder would receive approximately 200 ECU and any value above 0.5 leaves less endowment in absolute terms for each successive generation. The average claim of 0.63 in ug 5 leaves approximately 60 ECU for the responder, and the average claim of 0.78 in ug3 leaves only 10 ECU for the responder. We have to stress that any differences between games with accepted and rejected proposals are not statistically significant because of the relatively low number of proposals that were rejected.

Table 2 also details the average standard deviation of payoffs within each group. This measure of inequality within groups was generally lower in ultimatum games. This finding is particularly interesting in the comparison of ug3plus2 and dg5, two treatments with the same number of generations. The mean payoff in ug3plus2 was as high as the one in $d g 5$. Therefore, in both treatments the resource was used equally efficiently, despite the costs of punishment in ug3plus2. The average standard deviation however was much lower in ug3plus2, indicating that the resource

\footnotetext{
${ }^{1}$ Pre-veto players are those before the responder in the ultimatum games; the last player by design keeps $100 \%$ of the passed-on amount.
} 


\begin{tabular}{lrrrrrr}
\hline & \multicolumn{2}{c}{ Payoff } & & \multicolumn{3}{c}{ Claim of pre-veto players } \\
\cline { 2 - 3 } \cline { 5 - 6 } Game & Mean & Std. & Offer to last & Overall & Accepted & Rejected \\
\hline dg5 & 148 & 125 & 51 & 0.58 & - & - \\
ug5 & 108 & 30 & 90 & 0.55 & 0.51 & 0.63 \\
dg3 & 182 & 160 & 71 & 0.64 & - & - \\
ug3 & 162 & 72 & 182 & 0.53 & 0.48 & 0.78 \\
ug3plus2 & 144 & 85 & 70 & 0.57 & 0.55 & 0.73 \\
\hline
\end{tabular}

Table 2: Mean payoffs, the standard deviation of payoffs within each group, the amount offered to the last player, and the ratio of the endowment claimed by pre-veto players. Claims are listed separately for ultimatum games in which responders accepted/rejected.

was shared more fairly. As previously discussed, the threat of a veto disciplined early generations in their claims and led to fairer resource sharing. Nevertheless, the downside of this greater fairness was the very costly punishment implemented by the last generation. That ug3plus2 was, despite the costs of punishment, just as efficient as $d g 5$, suggests that veto power, in combination with the responsibility of the veto-empowered generation towards future generations can lead to a fairer distribution of a shared resource without excessive losses in efficiency.

We also tested whether there were path dependencies for the claims of players, that is, whether earlier players set an example that later generations followed. We tested this pattern through predicting, in a linear regression model, the ratio of the resource taken by player 2 from the ratio taken by player 1 . If player 1 claimed all the resources available to him or her, it was not possible to calculate this ratio for player 2. Therefore, such groups (11.5\% of all groups) are not included in the following analysis. The same model also tested whether the extent to which players 2 followed the example set by players 1 depended on the type of game played and the amount of generations in the chain. The positive estimate in table 3 for the ratio taken by $\mathrm{P} 1$ reveals that players 2 did follow the example set by the first players. This effect did not interact with the length of the generational chain or the type of game for player 2. This finding implies that player 1 did not only have the greatest control over how much resources were available to later generations, but also set the stage for how fairly other players would share the remainder of the resource. As with players 1 in Table 2, the claims of players 2 were lower in ultimatum games and did not depend on the amount of subsequent generations.

\begin{tabular}{lrcc}
\hline & Estimate & {$\left[\mathrm{CI}_{95}\right]$} & $p$ \\
\hline Intercept & 0.4840 & {$[0.3463 ; 0.6217]$} & 0.0005 \\
Ratio player 1 & 0.5397 & {$[0.2886 ; 0.7908]$} & 0.0321 \\
Ultimatum & -0.1539 & {$[-0.2213 ;-0.0865]$} & 0.0228 \\
5 generations & 0.0133 & {$[-0.0201 ; 0.0467]$} & 0.6902 \\
Ratio p1 $\times$ ultimatum & 0.0430 & {$[-0.0772 ; 0.1632]$} & 0.7208 \\
Ratio p1 $\times 5$ generations & -0.0552 & {$[-0.1152 ; 0.0048]$} & 0.3576 \\
\hline$R^{2}$ & 0.161 & & \\
\hline
\end{tabular}

Table 3: OLS estimates predicting the claimed ratio by player 2 (treatment ug3plus2 excluded). 


\section{Discussion}

We find clear evidence that giving veto power to later generations in a chain of inter-generational dependencies reduces egoism in early generations and promotes the sustainable and fair use of resources. In inter-generational chains without veto power, the last generation received on average only half of the amount that they received in cases with veto power. Therefore, we find clear evidence for a dictatorship of the present. Furthermore, we find that in order to achieve an efficient and responsible use of veto power, the veto-empowered generation must take into account the consequences of their veto for subsequent generations.

The results of the experiment indicated that players whose position in the intergenerational chain was close to that of the veto-empowered players over-consumed resources just as much (in relative amounts) as players who came before them. This result explains why overall injustice towards later generations tended to be the highest in long generational chains. Furthermore, the accumulation of injustice towards the last generation probably led to the high rejection rate of the vetoempowered players in treatments with long generational chains. This finding implies that the more injustice could accumulate, the higher the costs for total welfare due to the use of the veto power. Therefore, it is preferable that the veto decision makers are as close as possible to the over-consuming generations to minimize the accumulation of injustice.

The fact that all pre-veto players claimed roughly the same relative amount of the endowment is also notable because it indicates that (1) early players do not feel a greater responsibility to restrain their egoism if there are more generations that depend on their choice and (2) generations follow the example set by previous generations. Thus, early generations do not play a key role only in the sustainable use of a resource, but also in sustaining norms of fairness (inter-generational equity) in later generations.

Overall, our results suggest that only resource utilization paths qualifying as 'fair' or 'sustainable' will achieve the consent of later generations. Highly unequal distributions benefiting earlier generations will be prevented by later veto players, even when it creates large welfare losses. The more biased the utilization of a renewable resource, the more likely is 'revenge' from later generations. In intergenerational dynamics, as unfairness increases, the personal costs of destruction decrease.

The usual words of caution apply when generalizing from behavioral experiments in a theoretical game setting to real-world problems. Perhaps the most drastic simplification in our design is that generations were represented by individuals in the experiment. This factor eliminates any possibility of within-generation interaction, and individuals are known to behave differently from groups (Charness et al. 2007; Bornstein and Yaniv 1998). In addition, unlike in a real-world setting, the time horizon over which decisions had to be made was drastically shorter and there was no uncertainty with respect to the resource regrowth. Additionally, we abstracted from overlapping-generations dynamics.

Despite the limitations in our design, our results are not only of hypothetical interest. Fridays for Future activists recently argued that those currently in charge - be it as holders of powerful political positions, as business leaders, or as voters and 
customers - are largely responsible for climate change and for the lack of effective action. If in 20-30 years the consequences of climate change are devastating and today's adolescent activists suffer from its consequences, it is plausible that the then-retired generation will be held accountable for their reluctance of 30 years prior. As the elderly depend to some extent on the goodwill of the younger, the middle-generation in 2050 may retaliate against the previous generation(s). Several institutions, such as veto councils (Padilla 2002) have been proposed to manage inter-generational sharing, but none have gained significant prominence. Any such institution should help prevent retaliation by later generations. Therefore, it is also in the interest of the generations currently in power to establish such institutions.

On a broader note, our results suggest that granting the young generation power in the decision making process is an underutilized route towards sustainable resource use. Such a power transfer has only recently started and is achieved in very small steps. Institutions designed to overcome the social dilemma of climate change often deal with the redistribution of resources within generations (e.g., between countries), and most decision makers within such institutions come from the same generation. In most countries, the average age of political elites is at least 55 years and increasing (Manning 2017; Li 2012), which is the exact opposite of what our results suggest is desirable. Nevertheless, the (self-)empowerment of the young generation in the form of globally coordinated Friday for Futures demonstrations and the prominence of representatives of the young generation at recent UN climate summits reflects a promising step towards the involvement and contribution of the young generation.

\section{Acknowledgements}

The research presented in this article was supported by the Linnaeus University Center for Data Intensive Sciences and Applications, DISA. We thank Giangiacomo Bravo for feedback on the paper.

\section{Authors contributions}

M.F. and S.W. planned the research and wrote the paper. M.F. conducted the experiment and analyzed the data.

\section{Declaration of interest}

The authors have no competing interests.

\section{References}

Bahr, G., Requate, T., 2014. Reciprocity and giving in a consecutive three-person dictator game with social interaction. German Economic Review 15 (3), 374-392.

Bornstein, G., Yaniv, I., 1998. Individual and group behavior in the ultimatum game: are groups more "rational" players? Experimental Economics 1 (1), 101-108.

Charness, G., Gneezy, U., 2008. What's in a name? anonymity and social distance in dictator and ultimatum games. Journal of Economic Behavior \& Organization 68 (1), $29-35$. 
Charness, G., Rigotti, L., Rustichini, A., 2007. Individual behavior and group membership. American Economic Review 97 (4), 1340-1352.

Chen, D. L., Schonger, M., Wickens, C., 2016. oTree: An open-source platform for laboratory, online, and field experiments. Journal of Behavioral and Experimental Finance 9, 88-97.

Cooper, D. J., Dutcher, E. G., 2011. The dynamics of responder behavior in ultimatum games: A meta-study. Experimental Economics 14 (4), 519-546.

De Geest, L. R., Stranlund, J. K., Spraggon, J. M., 2017. Deterring poaching of a common pool resource. Journal of Economic Behavior \& Organization 141, 254-276.

Delaney, J., Jacobson, S., 2016. Payments or persuasion: common pool resource management with price and non-price measures. Environmental and Resource Economics 65 (4), 747-772.

DemocracyNow, 2019. We are striking to disrupt the system. https://www . democracynow.org/2019/9/11/greta_thunberg_swedish_activist_climate_ crisis, accessed: 2020-03-05.

Engel, C., 2011. Dictator games: A meta study. Experimental Economics 14 (4), 583-610.

Farjam, M., 2020. The bandwagon effect in an online experiment with real political organisations. International Journal of Public Opinion Research, edaa008.

Farjam, M., Nikolaychuk, O., Bravo, G., 2019. Experimental evidence of an environmental attitude-behavior gap in high-cost situations. Ecological Economics 166, 106434.

Fehr, E., Schmidt, K. M., 1999. A theory of fairness, competition, and cooperation. The quarterly journal of economics 114 (3), 817-868.

Fischer, M.-E., Irlenbusch, B., Sadrieh, A., 2004. An intergenerational common pool resource experiment. Journal of environmental economics and management 48 (2), 811836.

Gampfer, R., 2014. Do individuals care about fairness in burden sharing for climate change mitigation? evidence from a lab experiment. Climatic change 124 (1-2), 65-77.

Georgescu-Roegen, N., 1975. Energy and economic myths. Southern economic journal, 347-381.

Grolleau, G., Sutan, A., Vranceanu, R., 2016. Do people contribute more to intra-temporal or inter-temporal public goods? Research in Economics 70 (1), 186-195.

Güth, W., Kocher, M. G., 2014. More than thirty years of ultimatum bargaining experiments: Motives, variations, and a survey of the recent literature. Journal of Economic Behavior \& Organization 108, 396-409.

Güth, W., Schmittberger, R., Schwarze, B., 1982. An experimental analysis of ultimatum bargaining. Journal of economic behavior \& organization 3 (4), 367-388.

Hauser, O. P., Rand, D. G., Peysakhovich, A., Nowak, M. A., 2014. Cooperating with the future. Nature 511 (7508), 220.

Janssen, M. A., Anderies, J. M., Joshi, S. R., 2011. Coordination and cooperation in asymmetric commons dilemmas. Experimental Economics 14 (4), 547.

Kabeer, N., 2000. Inter-generational contracts, demographic transitions and the 'quantityquality'tradeoff: parents, children and investing in the future. Journal of International Development: The Journal of the Development Studies Association 12 (4), 463-482.

Kahneman, D., Knetsch, J. L., Thaler, R. H., 1986. Fairness and the assumptions of economics. Journal of business, S285-S300.

Kasser, T., 2011. Cultural values and the well-being of future generations: A cross-national study. Journal of Cross-Cultural Psychology 42 (2), 206-215.

Konow, J., 2003. Which is the fairest one of all? a positive analysis of justice theories. Journal of economic literature 41 (4), 1188-1239. 
Li, C., 2012. Preparing for the 18th party congress: Procedures and mechanisms. China Leadership Monitor 36 (6).

Lopez, M. C., Villamayor-Tomas, S., 2017. Understanding the black box of communication in a common-pool resource field experiment. Environmental Science \& Policy 68, 69-79.

Mallucci, P., Wu, D. Y., Cui, T. H., 2019. Social motives in bilateral bargaining games: How power changes perceptions of fairness. Journal of Economic Behavior \& Organization 166, 138-152.

Manning, J. E., 2017. Membership of the 115th congress: A profile. Tech. rep., CRS Report.

Osés-Eraso, N., Viladrich-Grau, M., 2011. The sustainability of the commons: giving and receiving. Experimental Economics 14 (4), 458.

Oullier, O., 2013. Behavioural insights are vital to policy-making. Nature 501, 463.

Padilla, E., 2002. Intergenerational equity and sustainability. Ecological Economics 41 (1), 69-83.

Riedl, A., Vyrastekova, J., et al., 2003. Responder behavior in three-person ultimatum game experiments. CentER for Economic Research discussion paper, Tilburg University.

Sadrieh, A., et al., 2003. Equity versus warm glow in intergenerational giving. Tilburg University.

Schuppert, F., 2011. Climate change mitigation and intergenerational justice. Environmental Politics 20 (3), 303-321.

Velez, M. A., Stranlund, J. K., Murphy, J. J., 2009. What motivates common pool resource users? experimental evidence from the field. Journal of Economic Behavior \& Organization 70 (3), 485-497.

Walker, A., 1996. The new generational contract: intergenerational relations, old age and welfare. Psychology Press. 


\section{Appendix}

\subsection{Sample demographics}

Subjects were randomly assigned to one of the five treatments. Table 4 shows that this lead to an almost equal distribution of demographics across treatments.

\begin{tabular}{|c|c|c|c|c|c|c|}
\hline \multirow[t]{2}{*}{ treatment } & \multicolumn{2}{|l|}{ age } & \multicolumn{2}{|c|}{ political preference } & \multirow{2}{*}{$\begin{array}{l}\text { female } \\
\text { proportion }\end{array}$} & \multirow{2}{*}{$\begin{array}{l}\text { Number of } \\
\text { groups }\end{array}$} \\
\hline & mean & std. & mean & std. & & \\
\hline dg3 & 34.21 & 9.53 & 3.87 & 3.14 & 0.49 & 33 \\
\hline $\operatorname{dg} 5$ & 35.90 & 9.93 & 3.93 & 2.99 & 0.54 & 33 \\
\hline ug3 & 35.81 & 9.18 & 3.74 & 2.94 & 0.55 & 34 \\
\hline ug5 & 35.50 & 9.31 & 3.69 & 2.68 & 0.52 & 31 \\
\hline ug3plus2 & 35.28 & 10.03 & 3.82 & 2.93 & 0.54 & 32 \\
\hline
\end{tabular}

Table 4: Distribution of demographics across treatments. Political preferences were measured on a 0 -10 left-right scale. 